\title{
Study of the Optical Properties and Structure Zinc Oxide Thin Films Prepared by Spin Coating Technique
}

\author{
Said Benramache1,*, Boubaker Benhaoua ${ }^{2}$ \\ 1 Material Sciences Department, Faculty of Science, University of Biskra, Biskra 070000, Algeria \\ ${ }^{2}$ VTRS Laboratory, Institute of Technology, University of El-Oued, El-Oued 39000, Algeria
}

(Received 12 April 2016; published online 03 October 2016)

\begin{abstract}
We investigated the structural and optical properties of zinc oxide $(\mathrm{ZnO})$ thin film as the $\mathrm{n}$-type semiconductor. In this work, the sol-gel method used to fabricate $\mathrm{ZnO}$ thin film on glass substrate at different solution molarities of $0.1,0.3$ and $0.5 \mathrm{~mol} / \mathrm{l}$ of zinc acetate dehydrate. The DRX analyses indicated that the coated $\mathrm{ZnO}$ films exhibit an hexagonal structure wurtzite and (002) oriented with the maximum value of crystallite size $G=69.32 \mathrm{~nm}$ is measured wi $0.5 \mathrm{~mol} / \mathrm{l}$. The thin film exhibit an average optical transparency is over $80 \%$ at high molarity, in the visible region, found that the optical band gap energy was increased up to $3.25 \mathrm{eV}$ at $0.5 \mathrm{~mol} / \mathrm{l}$. The minimum value of Urbach energy of $\mathrm{ZnO}$ thin film was achieved with $0.5 \mathrm{~mol} / \mathrm{l}$.
\end{abstract}

Keywords: $\mathrm{ZnO}$, Thin film, Precursor molarity, Sol-Gel technique.

DOI: 10.21272/jnep.8(3).03014

PACS numbers: 77.55.hf, 81.20.Fw

\section{INTRODUCTION}

Investigation of nanostructured depends on the size, structure and controlled optical properties of nanomaterials, where understanding the growth mechanism and growth parameters of nanostructured materials is essential. Zinc oxide has a wurtzite structure, this is a hexagonal crystal structure, $\mathrm{ZnO}$ is available as large bulk single crystals with lattice parameter $a=0.3249 \mathrm{~nm}, c=0.5206 \mathrm{~nm}$ belonging to the space group $\mathrm{P} 63 \mathrm{mc}$, and is characterized by two interconn-ecting sublattices of $\mathrm{Zn}^{2+}$ and $\mathrm{O}^{2-}$, such that each $\mathrm{Zn}$ ions is surrounded by a tetrahedral of $\mathrm{O}$ ions, and vice-versa [1-3].

$\mathrm{ZnO}$ is a very most important semiconductor material due to its applications [4]. It has a direct and wide band gap of $3.3 \mathrm{eV}$ in the near-UV spectral region [5], and a large exciton binding energy (60 meV) at room temperature [6]. Its consider that the $\mathrm{ZnO}$ is an $\mathrm{n}$ type semiconducting with high density and good crystal-line quality [7], but the use of $\mathrm{ZnO}$ as a semiconductor in electr-onic devices due to the high transmittance and good electrical conductivity [8]. Therefore, $\mathrm{ZnO}$ thin films are promising candid-ates for applications in shortwavelength light-emitting devices, lasers, field emission devices, solar cells and sensors [4-10].

Nanocrystalline $\mathrm{ZnO}$ thin films can be produced by several techniques such as reactive evaporation [11], molecular beam epitaxy (MBE), magnetron sputtering technique [12,13], pulsed laser deposition (PLD) [14], spray pyrolysis [15], sol-gel process [16], chemical vapor deposition, and electrochemical deposition [17].

In this work, $\mathrm{ZnO}$ film grown on glass substrate by (spin coating) sol-gel method at different solution molarities using with zinc acetate dehydrate as a primary material.

\section{MATERIALS AND METHODS}

\footnotetext{
* saidbenramache07@gmail.com
}

$\mathrm{ZnO}$ thin film grown on glass substrate using spin coating method, $\mathrm{ZnO}$ solution were prepared by dissolving $0.1,0.3$ and $0.5 \mathrm{~mol} / \mathrm{l}\left(\mathrm{Zn}\left(\mathrm{CH}_{3} \mathrm{COO}\right)_{2}, 2 \mathrm{H}_{2} \mathrm{O}\right)$ in the solvent containing equal volume absolute methanol solution $\left(\mathrm{CH}_{3} \mathrm{OH}\right)(99.995 \%)$ purity, then have added a drops of monoethanolamine solution as a stabilized, the mixture solution was stirred an heated at $50{ }^{\circ} \mathrm{C}$ for $6 \mathrm{~h}$ to yield a clear and transparency solution.

The solution was then spin coated onto the glass substrate, which were rotated at $4000 \mathrm{r} / \mathrm{min}$ for $50 \mathrm{~s}$. The films were dried in air at $200{ }^{\circ} \mathrm{C}$ for $30 \mathrm{~min}$ on a hot plate. The procedure from coating to drying was repeated 6 times, the resulting thin films were annealed at $600{ }^{\circ} \mathrm{C}$ in air for $2 \mathrm{~h}$.

Crystallographic and phase structure of the thin film was determined by X-ray diffraction (XRD, Bruker AXS-8D) with CuKa radiation $(\lambda=0.15406 \mathrm{~nm})$ in the scanning range of $(2 \theta)$ was between $30^{\circ}$ and $50^{\circ}$. The optical transmittance of the deposited film was measured in the range of $300-900 \mathrm{~nm}$ by using an ultraviolet-visible spectrophotometer (LAMBDA 25).

\section{RESULTS AND DISCUSSIONS}

The crystal structure of deposited $\mathrm{ZnO}$ film was studied using X-ray diffraction (XRD). XRD spectra of $\mathrm{ZnO}$ films as a function of solution molarities are showed in Figure 1. As can be seen, the diffraction peaks were observed at $2 \theta=31.8^{\circ}, 34.7^{\circ}, 36.5^{\circ}$ and $47.50^{\circ}$ which are related to the following plans (100), (002), (101) and (102) respectively. The film exhibit polycrystalline structure that belongs to thehexagonal wurtzite type of $\mathrm{ZnO}$.

In order to attain the detailed structure information, the grain size G (002) along the c-axis was calculated according to the Scherer's equation [18]: 


$$
G=\frac{0.9 \lambda}{\beta \cos \theta}
$$

where $G$ is the crystallite size, $\lambda$ is the X-ray wavelength $\left(\lambda=1.5406 \mathrm{~A}^{\circ}\right), \beta$ the full width at halfmaximum (FWHM), and $\theta$ is Bragg angle of the diffraction peaks were estimated in Table 1 .

According to the hexagonal symmetry, the lattice constant can be calculated by the following formula [18]:

$$
d_{h k l}=\left(\frac{4}{3} \frac{h^{2}+h k+k^{2}}{a^{2}}+\frac{l^{2}}{c^{2}}\right)^{-\frac{1}{2}}
$$

where $a, c$ are the lattice parameters, $(h, k, l)$ are the Miller indices of the planes and $d_{h k l}$ is the interplanar spacing.

The lattice parameters are substrate dependant. This gives rise to a mismatch between the substrate and the deposited thin films. The latter is responsible of the resulting strains and stresses. We estimated the strain $\varepsilon$ values in each thin film deposition via the formula [19]:

$$
\varepsilon=\frac{c-c_{0}}{c_{0}} \times 100 \%
$$

where $\varepsilon$ is the mean strain in $\mathrm{ZnO}$ thin films, $c$ the lattice constant of $\mathrm{ZnO}$ thin films is $0.51952 \mathrm{~nm}$, and $c_{0}$ the lattice constant of bulk (standard $c_{0}=0,5206 \mathrm{~nm}$ ).

The variation of grain size and the average uniform strain of $\mathrm{ZnO}$ thin films as a function of precursor molarity as shown in Figure 2, be seen, the maximum grain size of the $\mathrm{ZnO}$ on glass substrate was $69.32 \mathrm{~nm}$ for $0.1 \mathrm{M}$, indicate that the enhancement of the crystallinity and c-axis orientation of $\mathrm{ZnO}$ thin films, Zhu et al [21]. The minimum value of strain was equal to $-1.37 \%$ measured in $\mathrm{ZnO}$ thin film for precursor molarity $0.5 \mathrm{M}$. The decreases of the strain (less defects) with precursor molarity indicated the increases of the crystallinity and c-axis orientation of $\mathrm{ZnO}$ thin films. We found that the crystallite size along height direction. Negative value of the strain in the film means that the sample is in a tensile condition.

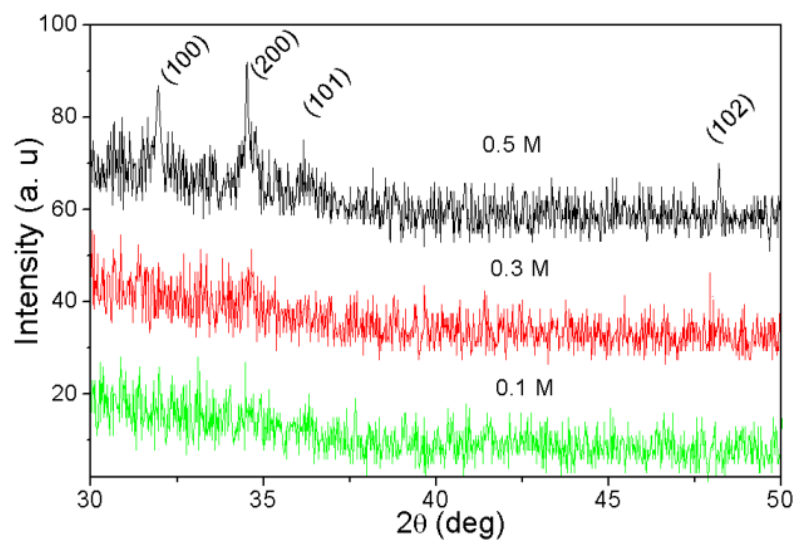

Fig. 1 - XRD spectrum of $\mathrm{ZnO}$ thin films prepared using spin coating method with different solution molarities

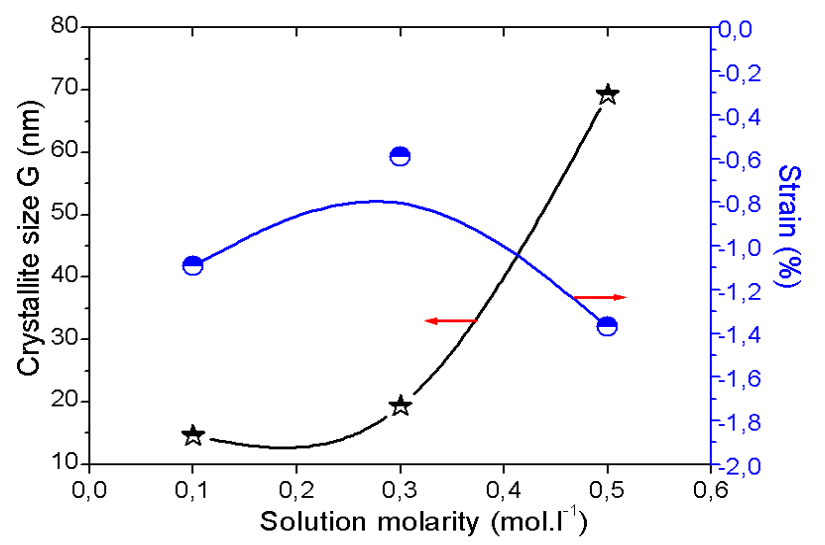

Fig. 2 - Variation of crystallite size and the strain $\varepsilon_{Z Z}$ for $(00$ 2) plane of $\mathrm{ZnO}$ thin films with different solution molarities

Table 1 - Bragg angle $2 \theta$, the full width at half-maximum FWHM $\beta$, the grain size $G$, lattice parameter $c$ and the strain $\varepsilon$ for (l $\left.\begin{array}{lll}0 & 0 & 2\end{array}\right)$ plane of $\mathrm{ZnO}$ thin films were measured as a function of annealing temperature

\begin{tabular}{|l|l|l|l|l|l|}
\hline $\begin{array}{l}\text { Solution } \\
\text { molarities }\end{array}$ & $2 \theta(\mathrm{deg})$ & $\begin{array}{c}\beta \\
(\mathrm{deg})\end{array}$ & $G(\mathrm{~nm})$ & $\begin{array}{l}c \\
(\mathrm{~nm})\end{array}$ & $\begin{array}{l}\varepsilon \\
(\%)\end{array}$ \\
\hline $0.1 \mathrm{M}$ & 34,48 & 0,57 & 14.59 & 5,19815 & $-1,09$ \\
$0.3 \mathrm{M}$ & 34,64 & 0,43 & 19.35 & 5,17487 & $-0,59$ \\
$0.5 \mathrm{M}$ & 34,52 & 0.12 & 69,32 & 5,19231 & $-1,37$ \\
\hline
\end{tabular}

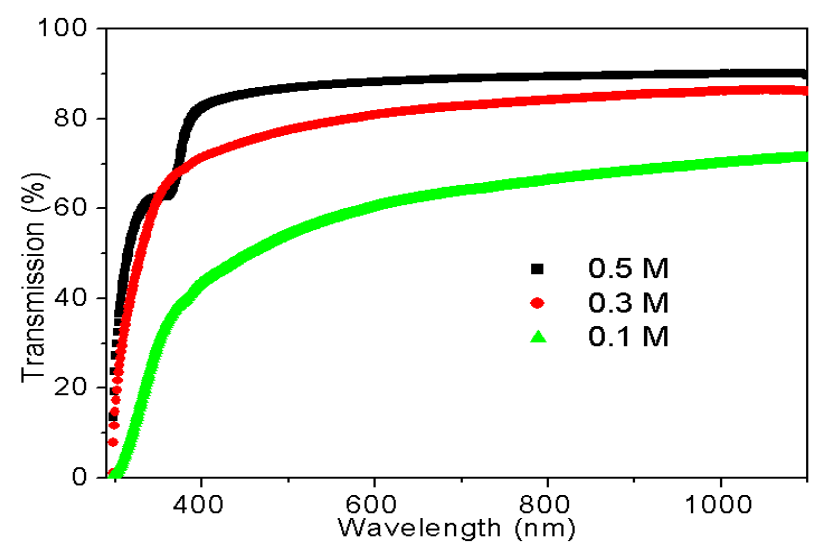

Fig. 3 - Transmission spectra $T(\lambda)$ of $\mathrm{ZnO}$ thin films as a function of solution molarity

The optical transmittance measured as a function of the wavelength is depicted in Fig. 3 shows the optical transmission spectra of $\mathrm{ZnO}$ thin films obtained at different precursor molarities. As can be seen, the transmittance of the films increased with increasing concentration of 0.1 to $0.5 \mathrm{M}$. A height transparent spectra $T(\lambda)$ with exhibited an average optical transparency over $80 \%$, in the visible range. The region of the absorption edge due to the transition between the valence band and the conduction band is located between $320-400 \mathrm{~nm}$, in this region the transmission decreased because of the onset fundamental absorption. At high concentration $\mathrm{ZnO}$ films may absorb strongly the visible light through intermediate gap states created by the film defects such as oxygen vacancies and interstitial zinc atoms.

$\mathrm{ZnO}$ is a semiconductor with a large direct band gap; the optical gap energy $E_{g}$ (Table 2) was obtained 
from the transmission spectra using the following relations [20]:

$$
(A h v)^{2}=C\left(h v-E_{g}\right)
$$

where $A$ is the absorbance, $C$ is a constant, $h v$ is the photon energy $\left(h v(\mathrm{eV})=\frac{1240(\mathrm{eV})}{\lambda(\mathrm{nm})}\right)$ and $E_{g}$ the band gap energy of the semiconductor. As it was shown in (Figure 4) a typical variation of $(A h v)^{2}$ as a function of photon energy ( $h v)$ used for deducing optical band gap $E_{g}$, it is determined by extrapolation of the straight line portion to zero absorption $(A=0)$ [12] the values of $E_{g}$ are listed in Table 2 . Besides, we have used the Urbach tail energy ( $\left.E_{u}\right)$, which is related to the disorder in the film network, as it is expressed follow [20]:

$$
A=A_{0} \exp \left(\frac{h v}{E_{u}}\right)
$$

where $A_{0}$ is a constant and $E_{u}$ is the Urbach energy.

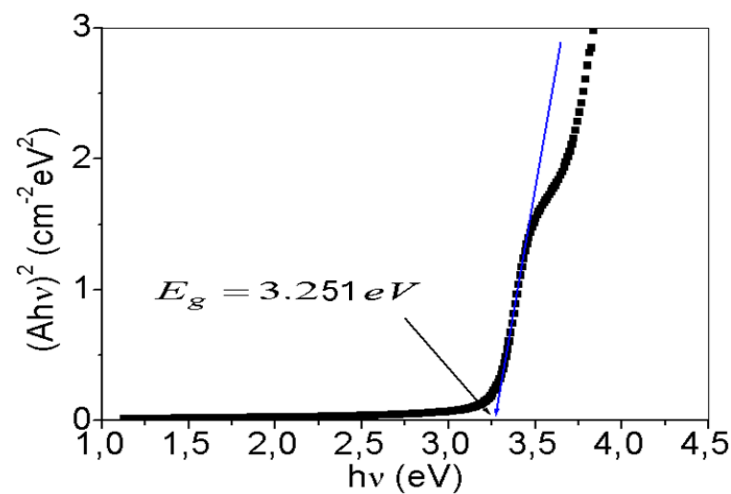

Fig. 4 - The typical variation of $(A h v)^{2}$ vs. photon energy of deposited $\mathrm{ZnO}$ thin film at $0.5 \mathrm{M}$

Figure 5 shows the variation of the band gap energy $E_{g}$ and the Urbach energy $E_{u}$ as a function of solution molarity. The optical gap and disorder vary inversely, it is observed that the band gap energy and Urbach energy of $\mathrm{ZnO}$ thin films decreased with increasing of solution molarity to minimum value was 0.1964 me at $0.5 \mathrm{M}$. the optical gap energy become increased from
2.87 to 3.25 , which may be attributed to the similar ionic radius between $\mathrm{O}$ and $\mathrm{Zn}$. This can be explained by increasing of the crystallite size (see Figure 2).

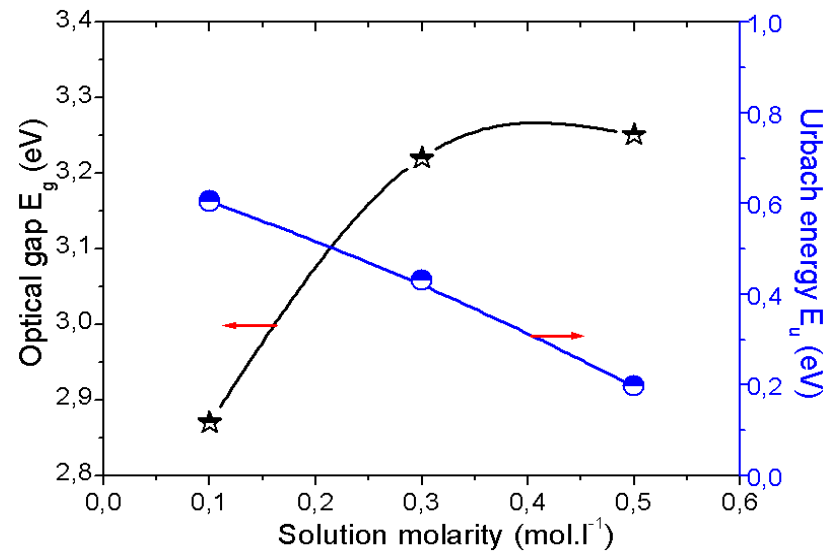

Fig. 5 - The variation of optical band gap $E_{g}$ and Urbach energy $E_{u}$ of $\mathrm{ZnO}$ thin films with different solution molarities

Table 2 - The optical properties of $\mathrm{ZnO}$ thin films

\begin{tabular}{|ccc|}
\hline $\begin{array}{l}\text { solution molarities } \\
\mathrm{mol} / 1\end{array}$ & $\begin{array}{c}E_{g} \mathrm{a} \\
(\mathrm{eV})\end{array}$ & $\begin{array}{c}E_{u} \\
(\mathrm{eV})\end{array}$ \\
\hline 0.1 & 2.870 & 0.605 \\
0.3 & 3.220 & 0.430 \\
0.5 & 3.251 & 0.197 \\
\hline
\end{tabular}

\section{CONCLUSIONS}

In conclusion, highly transparent conductive $\mathrm{ZnO}$ thin films were deposited on glass substrate by spin coating method. The $\mathrm{ZnO}$ thin films were deposited at different solution molarities using with zinc acetate dehydrate as a primary material. The effect of solution molarity on structural and optical properties of zinc oxide was investigated. The DRX analyses indicated that the coated $\mathrm{ZnO}$ films exhibit an hexagonal structure wurtzite and (002) oriented with the maximum value of crystallite size $G=69.32 \mathrm{~nm}$ is measured wi $0.5 \mathrm{~mol} / \mathrm{l}$. The thin film exhibit an average optical transparency is over $80 \%$ at high molarity, in the visible region, found that the optical band gap energy was increased up to $3.25 \mathrm{eV}$ at $0.5 \mathrm{~mol} / \mathrm{l}$. The minimum value of Urbach energy of $\mathrm{ZnO}$ thin film was achieved with $0.5 \mathrm{~mol} / \mathrm{l}$.

\section{REFERENCES}

1. S. Benramache, et al., Optik 125, 1303 (2014).

2. V.A. Coleman, C. Jagadish, Zinc Oxide Bulk Thin Films and Nanostructures Processing Properties and Applications (Elsevier Science, Gainesville, FL, USA, 2006).

3. M. Ohtsu, Progress in Nano-Electro Optics, VII (Springer: Tokyo : 2002).

4. X. Li, Y. Wang, W. Liu, G. Jiang, C. Zhu, Mater. Lett. 85 , 25 (2012)

5. S. Benramache, J. Nano- Electron. Phys. 8 No 1, 01008 (2016).

6. S. Benramache, B. Benhaoua, O. Belahssen, Optik 125,

5864 (2014).

7. E.A. Martín-Tovar, R. Castro-Rodríguez, A. Iribarren, Mater. Lett. 139, 352 (2015).

8. A. Mahroug, S. Boudjadar, S. Hamrit, L. Guerbous, Mater. Lett. 134, 248 (2014).

9. A.N. Reed, P.J. Shamberger, J.J. Hu, C. Muratore, J.E. Bultman, A.A. Voevodin, Thin Solid Films 579, 30 (2015).

10. S. Benramache, S. Gareh, B. Benhaoua, A. Darsouni, O. Belahssen, J. Chem. Mater. Res. 2 No 2, 59 (2015).

11. M. Alizadeh, V. Ganesh, A. Pandikumar, et al., J. Alloy. Compd. 670, 229 (2016)

12. B. Benhaoua, Superlattice. Microst. 68, 38 (2014). 
13. C.S. Tian, X.L. Chen, et al., Sol. Energ. Mater. Sol. C. 125, $59(2014)$

14. Y.D. Ko, K.C. Kim, Y.S. Kim, Superlattice. Microstr. 51, 933 (2012)

15. E.F. Keskenler, G. Turgut, S. Dogăn, Superlattice. Microst. 52, 107 (2012)

16. A. Mahroug, S. Boudjadar, S. Hamrit, L. Guerbous, Mater Lett. 134, 248 (2014).
17. E.A. Martín-Tovar, R. Castro-Rodríguez, A. Iribarren, Mater. Lett. 139, 352 (2015).

18. S. Benramache, B. Benhaoua, Superlattice. Microst. 52 1062 (2012).

19. A. Gahtar, et al., J. Semiconductors 34, 073001 (2013).

20. Yacine Aoun, Boubaker Benhaoua, Said Benramache, J. Nano- Electron. Phys. 7 No 3, 03006 (2015). 